\title{
The Impact of Pre-reading and Inserted Questions on Incidental Vocabulary Learning and Retention
}

\author{
Ali Forutan \\ Islamic Azad University Najafabad Branch, Iran \\ Email: forutanali@yahoo.com
}

\begin{abstract}
One basic objective of research in the field of ESL/EFL acquisition is to provide useful techniques for teaching and learning vocabulary in language classrooms. In this study attempt has been made to investigate the role of pre-reading questions and inserted questions on incidental vocabulary learning and retention. To achieve this goal, 60 selected homogeneous intermediate learners, according to their scores on the Oxford Placement Test (OPT) and by using match-pair design, were divided into two homogeneous groups of $A$ and B. Two weeks after the pretest, the treatment started. Each group received a different treatment. After a limited time when the learners finished reading passages an incidental vocabulary learning test which contained 8 questions was administered and this procedure, continued for 5 sessions. Then two weeks after the last session of the treatment a posttest was administered to measure the retention of incidentally learned vocabulary. The statistical analysis of the data showed that group B outperformed group A in terms of the number of words learned incidentally so the first null hypothesis was rejected. Also the results showed that group B performed better than group $A$ in the retention of the number of words learned incidentally; therefore, the second null hypothesis also was rejected.
\end{abstract}

Index Terms - top-down process, retention, incidental learning

\section{INTRODUCTION}

Reading is a skill of paramount importance. In many instances around the world it can be considered as the most important foreign language skill, particularly in cases where students have to read English material for their own specialist subject but may never actually have to speak the language: such cases are often referred to as "English as a library language" (Alderson,2002).

Language students need large amounts of comprehensible input, and reading materials provide the most readily available source (Chastain, 1988). Research has confirmed that reading in either a first (L1) or second (L2) language has a positive impact on language development, an impact that has been referred to as 'the power of reading' (Krashen, 1989). Whatever language development that occurs as a result of reading is said to occur incidentally (or secondarily) in that the reader's primary task is to make meaning from the text rather than learn new words or learn to spell better. Language development is an additional benefit of reading: it is the bonus that readers receive. The indisputable linguistic gain that readers receive from reading is new vocabulary, be it partial or complete knowledge of a word's meaning (For L1: Anderson, 1995; and for L2: Rott et al., 2002).

Vocabulary is the most central element in the social system of communication (Harley, 1995). This view is strengthened by McCarthy (1990) who claims that "without words to express a wide range of meanings, communication in L2 cannot happen". Richards (1998) maintains that vocabulary is the core component of language proficiency and provides much of the basis for how well learners speak, listen, read, and write. Without an extensive vocabulary and strategies for acquiring new vocabulary, learners often achieve less than their potential and may be discouraged from making use of language learning opportunities around them. Many researchers in the field of language learning and teaching believe that there is a symbolic relationship between reading and vocabulary acquisition. It is a proven fact that learners with high level comprehension skills are able to acquire broader and deeper vocabularies and learners with larger vocabularies are able to comprehend text better (Rott et al., 2002).

An assumption shared by many language-learning researchers is that much of second language vocabulary is acquired incidentally during reading for meaning (Krashen, 1989; Rott, 2002). Reader's age, reading skill, text and word characteristics, vocabulary size, readers' existing topic knowledge and familiarity with concept presented by unknown words, are pinpointed as factors influencing incidental word learning from context. The impact of reading tasks on incidental vocabulary learning and retention has long been established. It is also believed that different reading tasks impose different levels of engagement with the text and thus leading to different amounts of vocabulary achievement and retention.

\section{RESEARCH QUESTIONS}

According to what has been said so far, the following questions were addressed in this study:

1. Does the inclusion of pre-reading questions and inserted questions account for different amounts of incidental 
vocabulary learning from text?

2. Does the inclusion of pre-reading and inserted questions have an impact on student's retention of incidentally learned vocabulary?

\section{RESEARCH HYPOTHESES}

Based on the question posed by the researcher, the following null hypotheses were proposed to be tested:

H01: There is no significant relationship between the location of the reading questions in the text (pre-reading questions and inserted reading questions) and incidental vocabulary learning.

H02: There is no meaningful relationship between the location of reading questions (pre-reading questions and inserted reading questions) and retention of the incidentally learned vocabulary.

\section{METHOD}

\section{A. Participants}

A total of 88 male and female students studying English at the intermediate level at Pazhooheshgaran Language Institute in Shahinshahr were initially selected for this study. To determine the homogeneity of the subjects, an Oxford Placement Test (OPT) test consisting of the vocabulary and structure parts was administered. Then 60 students with intermediate level of proficiency, according to OPT chart, were selected and, by using match-pair design, were divided into two groups of 30, namely, Group A and Group B. Group A received their reading texts with pre-reading questions and Group B received their reading text containing inserted questions.

\section{B. Instrumentation}

The instruments to serve the purposes of this researcher were the following:

1. An Oxford Placement Test (OPT) comprising of the vocabulary and structure sections to ensure the homogeneity of the subjects.

2. A pretest consisting of 60 multiple-choice vocabulary questions which contained the vocabulary which was intended to be tested at the end and the rest were distractors. The reason for the pretest was to select the vocabulary which was new to the students.

3. A number of informative reading texts for the two groups. The texts were about 200 words in length and approximately at the same level of difficulty like the passages in students' course book (Mosaic 1, Reading). The reading texts for Group A contained pre-reading questions while the texts intended for Group B contained inserted questions scattered throughout the body of the texts.

4. A number of vocabulary tests which were administered after each session of the treatment.

5. A forty-item teacher-made vocabulary test which contained the vocabulary items tested after each session and was administered two weeks after the last session to check the retention of the incidentally learned vocabulary.

In order to make sure about the validity of the tests, three university professors were consulted and they approved that the test items were well-prepared and served the intended purpose.

\section{Procedure}

First, in order to have 60 homogeneous students, an Oxford Placement Test (OPT) was administered to 88 students studying at intermediate level at Pazhooheshgaran Language Institute. Then, according to OPT level chart, 60 intermediate students were selected and were divided into two 30-student groups, namely, group A and group B.

The next step was to decide about the vocabulary. To do so, a number of words were selected and in order to make sure that these words are unknown for the students, a pretest was prepared comprising 60 multiple-choice items containing the intended words. After the test the words which were unfamiliar to the students were selected. In other words, the researcher came up with 40 unfamiliar words and included these words in his experiment.

Then after two weeks the treatment started. For the treatment, the two groups read the same texts but the nature and the kind of tasks expected from them were different. In other words, Group A read the texts containing some pre-reading questions. Group B read the same texts with the same questions, but this time the questions were scattered throughout the body of the text (inserted questions).

The researcher himself conducted the research in the two classes. Students were told that the researcher was only interested in the way they read. They were told to try to find correct answers to the questions. The researcher did his best not to direct students' attention to vocabulary. He did not tell the students about the upcoming vocabulary test. The procedures for conducting the classes were as follows:

First, a "warm-up" was conducted and the students were introduced to the text. Then the passages were handed out. In order to set a time limit for the students' reading, the researcher asked four teachers to read the text and the question.

Then, after they finish reading their texts, the reading passages were collected and the subjects were allowed a five-minute break. After the break, the incidental vocabulary learning test, which comprised 8 questions, was administered. This procedure was followed in each session for five sessions. After the last session, for two weeks there was no test or treatment. Then the post-test which was a combination of all tests given to the students after each session 
was conducted to measure the students' retention of the incidentally learned vocabulary.

\section{Data Analysis}

In order to fulfill the objectives of this study the following statistical analyses were employed.

Analysis No. 1: Analysis No. 1 was a descriptive analysis of the whole subjects' performance on the OPT in order to select a homogeneous group of subjects for the study.

Analysis No. 2: A number of t-tests were run, one to compare the means of the two groups after each session with respect to incidental vocabulary learning, and one to compare the means of the two groups with respect to the retention of the incidentally learned vocabulary two weeks after the last session of the treatment.

\section{Results}

The results consist of two parts: part one includes the results of the tests which were administered after each session of the experiments and part two includes the results of the posttest which was carried on two weeks after the experiment.

\section{A. The Results of the Tests after Each Session}

As it was mentioned, the experiment went on for five sessions and after each session a test of vocabulary consisting of 8 multiple choice items which contained the intended vocabulary was conducted. Figure 4.1 shows a graphic representation of the results of the tests and Tables 4.1 through 4.5 below show the descriptive statistics and the results of the t-tests regarding these tests. It should be noted here that for the ease of comparison all the scores were converted to a scale of 20

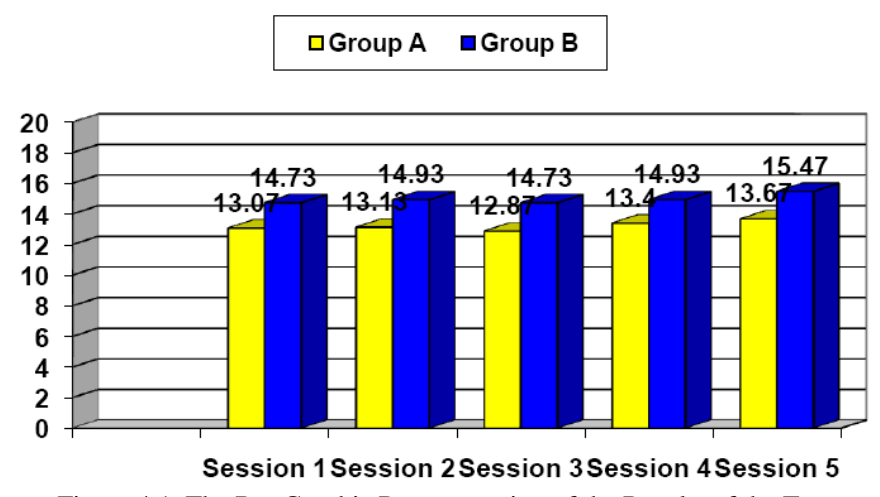

Figure 4.1. The Bar Graphic Representation of the Results of the Tests

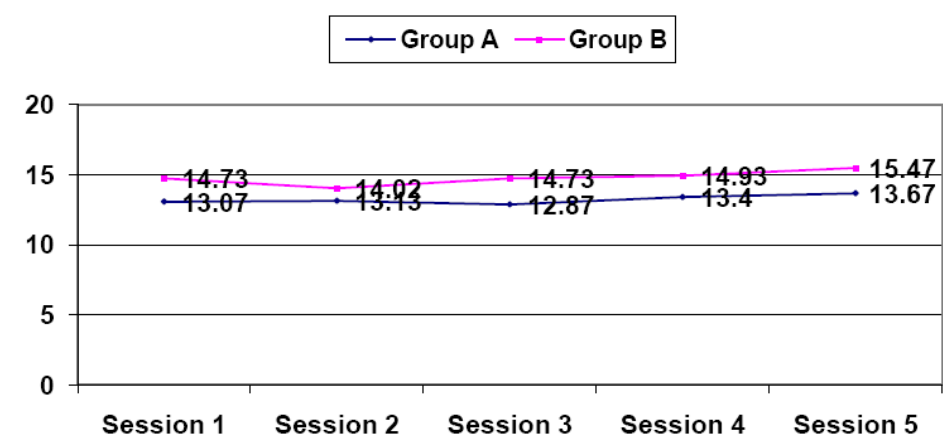

Figure 4.2. The Line Graphic Representation of the Results of the Tests

TABLE 4.1.

THE DESCRIPTIVE STATISTICS AND THE REASUlts OF THE T-TEST FOR SESSION 1A

\begin{tabular}{|l|l|l|l|l|l|l|l|}
\hline Group & No. & Mean & SD & SEM & Df & t & p \\
\hline A & 30 & 13.07 & 2.7 .66 & .505 & 58 & 2.405 & .019 \\
\hline B & 30 & 14.73 & 2.599 & .475 & & & \\
\hline
\end{tabular}

TABLE 4.2.

THE DESCRIPTIVE STATISTICS AND THE RESUlts OF THE T-TEST FOR SESSION 2

\begin{tabular}{|l|l|l|l|l|l|l|l|}
\hline Group & No. & Mean & SD & SEM & df & t & $\mathrm{p}$ \\
\hline A & 30 & 13.13 & 2.909 & .531 & 58 & 2.57 & .013 \\
\hline B & 30 & 14.93 & 2.504 & .457 & & & \\
\hline
\end{tabular}


TABLE 4.3.

THE DESCRIPTIVE STATISTICS AND THE RESUlTS OF THE T-TEST FOR SESSION 3

\begin{tabular}{|l|l|l|l|l|l|l|l|}
\hline Group & No. & Mean & SD & SEM & df & t & p \\
\hline A & 30 & 12.87 & 3.35 & .612 & 58 & 2.358 & .022 \\
\hline B & 30 & 14.73 & 2.75 & .5 .3 & & & \\
\hline
\end{tabular}

TABLE 4.4.

THE DESCRIPTIVE STATISTICS AND THE RESUltS OF THE T-TEST FOR SESSION 4

\begin{tabular}{|l|l|l|l|l|l|l|l|}
\hline Group & No. & Mean & SD & SEM & df & T & p \\
\cline { 1 - 5 } A & 30 & 13.4 & 3.069 & .56 & 58 & 1.97 & .054 \\
\hline B & 30 & 14.93 & 2.959 & .54 & & & \\
\hline
\end{tabular}

TABLE 4.5.

THE DESCRIPTIVE STATISTICS AND THE RESULTS OF THE T-TEST FOR SESSION 5

\begin{tabular}{|l|l|l|l|l|l|l|l|}
\hline Group & No. & Mean & SD & SEM & df & T & p \\
\hline A & 30 & 13.67 & 2.783 & .508 & 58 & 2.709 & .009 \\
\hline B & 30 & 15.47 & 2.345 & .428 & & & \\
\hline
\end{tabular}

As it can be seen in the above tables, the results of the t-tests for sessions 1, 2, 3, and 5 show a significant difference between the performances of the two experimental groups; that is, the group receiving inserted questions performed better than the group received pre-reading questions. The results of session 4 , however, show no significant difference between the results of the test of the two groups.

In order to find out about the total performances of the two groups, another t-test was run. Figure 4.3 shows a graphic representation of the results of this test and Table 4.6 descriptive statistics and the results of the t-test regarding this test.

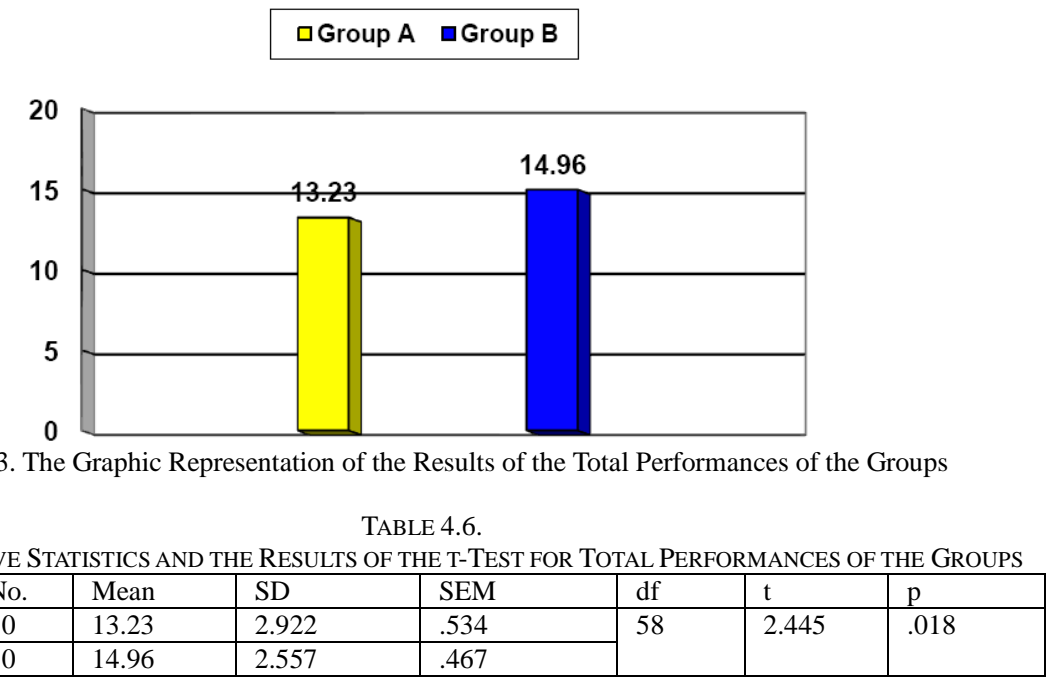

As it can be seen in the above table, the results of the t-test show that Group B, that is, the group receiving inserted questions outperformed Group A, that is, the group receiving pre-reading questions. This result rejects the first null hypothesis proposed in this study, that is, there is no significant relationship between the location of the reading questions in the text (pre-reading questions and inserted reading questions) and incidental vocabulary learning.

\section{B. The Results of the Posttest}

The next step was to review the results of the posttest which was administered two weeks after the completion of the experiment and through applying one last t-test compare the results of the performances of the two groups. Figure 4.3 shows a graphic representation of the results of the posttest and Table 4.7 below shows the results of the $t$-test. 


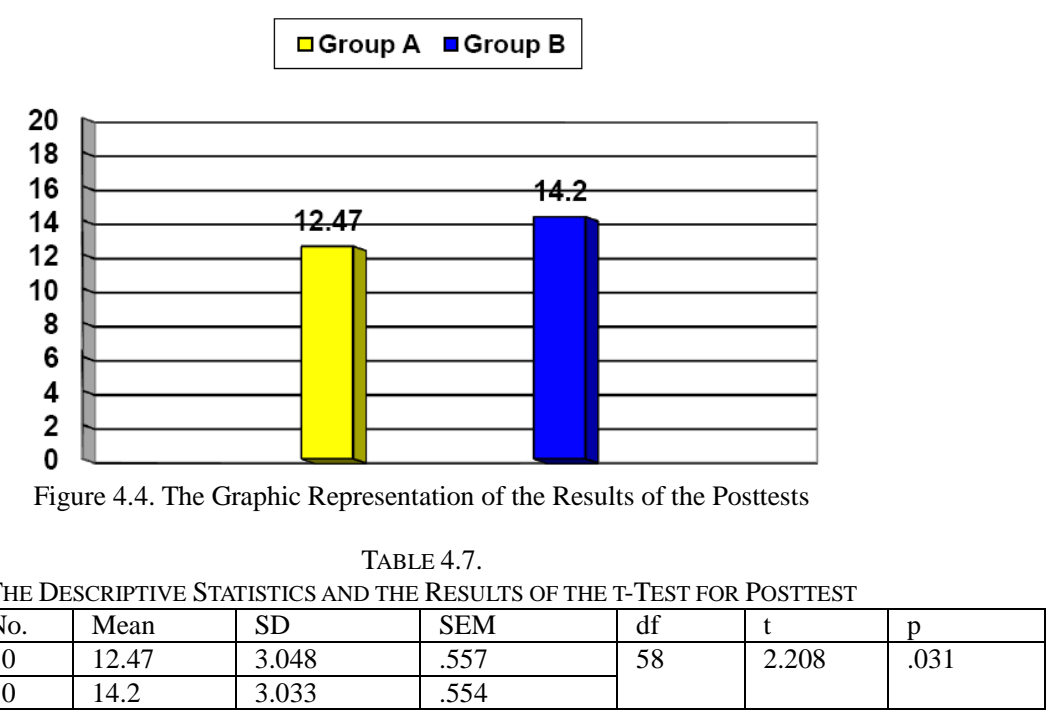

It can be seen in Table 4.7 that once again Group B, that is, the group with inserted questions, outperformed Group A, that is, the group with pre-reading questions. The results obtained rejects the second null hypothesis of this study which proposes that there is no meaningful relationship between the location of reading questions (pre-reading questions and inserted reading questions) and retention of the incidentally learned vocabulary.

\section{CONCLUSIONS}

The goal of this study was to determine the possible effects of different reading activities on vocabulary gain and the time these words are retained in the learners mind. Incidental vocabulary learning is a byproduct of reading which do not focus on vocabulary learning and many language learning researchers believe that for many learners much of second language vocabulary is acquired incidentally during reading for meaning (Rott et al., 2002). Incidental word learning is a slow and incremental process but it is valued in that learners do two things at once. As they read for comprehension they also expand their vocabulary. Coady (1979) after a review of second language research concludes that, the incidental acquisition hypothesis suggests that there is a gradual but steady incremental growth of vocabulary knowledge through meaningful interaction with texts. The incidental acquisition of vocabulary has been explained by Krashen (1989) in the context and framework of his Input hypothesis. According to this hypothesis, new, unfamiliar word is acquired when its significance is made clear to the learner.

Now given the high correlation with reading comprehension and incidental vocabulary gain we can conclude that teachers should pay more attention to this important source of vocabulary. Reading is a process in which the students who are more knowledgeable in vocabulary get richer. Therefore teachers should know that just providing students with reading materials without further aid does not lead to considerable amounts of vocabulary learning and longer retention.

As the findings of this study indicate, different reading tasks impose different levels of engagement with texts and thus lead to different amounts of vocabulary achievement and retention.

The results of this study showed the superiority of inserted questions over pre-reading questions in terms of degree of engagement with texts and amount of word learning. So teachers who seek vocabulary enrichment through reading are recommended to use tasks with higher involvement load.

\section{SUGGESTIONS FOR FURTHER STUDIES}

Reading comprehension still is a very complicated area for many researchers and lots of questions about it are unanswered. Therefore, regarding the importance of the subject, further research can be done.

The participants of this study were Iranian boys and girls, studying English at intermediate level of language proficiency. Future research can include students of other levels or other nationalities.

This study determined the impact of only two kinds of reading tasks on incidental vocabulary and retention. Another study may focus on other reading tasks and incidental vocabulary learning and retention.

The relationship between incidental vocabulary learning and retention, and individual differences like aptitude was not the focus of this study. Another study might investigate this issue.

The present study did not pay attention to variables such as age and gender. Other studies might explore the relationship between students' age and gender and incidental vocabulary learning and retention.

\section{REFERENCES}

[1] Alderson, J. C. (1995). Reading in a foreign language: A reading problem or a language problem? In J. C. Alderson, \& A. H. 
Urquhart (Eds.), Reading in a foreign language (pp. 1-24). New York Longman: Longman.

[2] Alderson, J. C. (2002). Assessing reading. Cambridge: Cambridge University Press.

[3] Chastain, K. (1988). Developing second language skills: Theory and practice. (3rd ed.). New York: Harcourt Brace Jovanovich, Inc.

[4] Coady, J. (1979). A psycholinguistic model of the ESL reader. In Mackay, R. et al. (EDS.): 5-12.

[5] Harley B.(1995). The lexicon in second language research. In Harely B. (1995), Lexical issues in language learning (pp. 1-20). Michigan: Research Club In Language Learning.

[6] Krashen, Stephen. (1989). Language acquisition and language education. Prentice Hall International.

[7] McCarthy, M. (1990). "vocabulary". Oxford University Press.

[8] Richards, J.C. (1998). Extensive reading in the second language classroom. Cambridge University Press.

[9] Rott, S., Williams, J. and Cameron, R. (2002). "The effect of multiple-choice L1 glosses and input-output cycles on lexical acquisition and retention". Language learning, 6/3: 183-222.

Ali Forutan is from Iran. He is an English instructor at the Islamic Azad University of Najafabad. He got his MA in TEFL from the Islamic Azad University of Najafabad and his BA in English Translation from the University of Allameh Tabatabae of Tehran. His areas of interest in doing research are teaching and learning language skills, sociolinguistics and syllabus design. 